Population Studies

A Journal of Demography

ISSN: 0032-4728 (Print) 1477-4747 (Online) Journal homepage: https://www.tandfonline.com/loi/rpst20

\title{
Does broadband Internet affect fertility?
}

\section{Francesco C. Billari, Osea Giuntella \& Luca Stella}

To cite this article: Francesco C. Billari, Osea Giuntella \& Luca Stella (2019): Does broadband Internet affect fertility?, Population Studies, DOI: 10.1080/00324728.2019.1584327

To link to this article: https://doi.org/10.1080/00324728.2019.1584327
(c) 2019 The Author(s). Published by Informa UK Limited, trading as Taylor \& Francis Group

\section{+ View supplementary material $\longleftarrow$}

曲 Published online: 28 Mar 2019.

Submit your article to this journal

View Crossmark data $₫$ 


\title{
Does broadband Internet affect fertility?
}

\author{
Francesco C. Billari ${ }^{1}$, Osea Giuntella ${ }^{2,3}$ and Luca Stella ${ }^{1,3}$ \\ ${ }^{1}$ Bocconi University, ${ }^{2}$ University of Pittsburgh, ${ }^{3}$ IZA
}

\begin{abstract}
The spread of high-speed (broadband) Internet epitomizes the digital revolution. Using German panel data, we test whether the availability of broadband influences fertility choices in a low-fertility setting well known for the difficulty in combining work and family life. We exploit a strategy devised by Falck and colleagues to obtain causal estimates of the impact of broadband on fertility. We find positive effects of broadband availability on the fertility of highly educated women aged 25-45. We further confirm this result using county-level data on total fertility. We show that broadband access significantly increases the share of women reporting home- or part-time working. Furthermore, we find positive effects on time spent with children and overall life satisfaction. Our findings are consistent with the hypothesis that access to broadband allows highly educated women, but not the less educated, to reconcile career and motherhood, which may promote a 'digital divide' in fertility.
\end{abstract}

Supplementary material for this article is available at: https://doi.org/10.1080/00324728.2019.1584327

Keywords: Internet; low fertility; work and family; teleworking; digital divide; SOEP; Germany

[Submitted April 2018; Final version accepted December 2018]

\section{Introduction}

The rapid diffusion of the Internet, and in particular of access to high-speed (broadband) Internet, has characterized the digital revolution that has modified our lives at the beginning of the twenty-first century. The profound social and economic implications of the Internet's spread have been underlined by social science scholars since its inception (Di Maggio et al. 2001; Castells 2002).

More recently, researchers have also started to focus on the effect that the Internet has on family life, both in terms of daily schedules and longerterm effects. Views and hypotheses have been diverse. For instance, the Internet has been variously portrayed as: a disruptive technology that threatens more traditional family life (Conley 2009); an emerging and potentially universal new social intermediary in the search for partners (Rosenfeld and Thomas 2012); and a technology that allows spillovers from work to family life, but also vice versa (Wajcman 2015).

Scholars interested in family and fertility have long focused on the importance of technological change. Boserup's (1976) theory of the demographic transition emphasizes the crucial importance of (endogenous) technological shifts in population change. Alongside the huge increases in women's education and labour force participation (Goldin and Katz 2002), shifts in contraceptive technology have been seen as a precondition for the massive reproductive changes taking place in high-income societies during the last part of the twentieth century, that is, the Second Demographic Transition (Lesthaeghe 2010). Other sources of technological change affecting family life, fertility decisions, and the labour force participation of women include household appliances (Greenwood et al. 2005; de V. Cavalcanti and Tavares 2008) and medical advances (Albanesi and Olivetti 2016). Household appliances, in particular, are seen as 'engines of liberation' that allow both partners to work for the market and, in principle, to experience fewer constraints in fertility choices.

In the era of very low and lowest-low fertility (Kohler et al. 2002; Billari and Kohler 2004), the possibility of combining parenthood with work has become a central issue (Morgan and Taylor 2006; Balbo et al. 2013). During the first half of the gender revolution, in particular, the opportunities 
for women to combine market work and family responsibilities are central in preventing the fall to lowest-low fertility (McDonald 2000; Goldscheider et al. 2015). The discussion around low fertility, however, has not so far focused on the role of broader technological change - with the digital revolution epitomizing such technological change-and how it could shape the future of fertility. An overarching research question is therefore this: can broadband be seen as an 'engine of liberation' that allows individuals to realize fertility desires and to combine work and family? If this is the case, and if we assume that desired fertility is higher than realized fertility in low-fertility societies (Goldstein et al. 2003; Philipov 2009), we expect access to broadband to be linked to higher fertility levels in highincome, low-fertility societies.

In this paper, we address this overarching question by analysing the impact of the diffusion of high-speed Internet on fertility choices in a low-fertility setting: Germany. Our analyses are driven by theoretical considerations on the potential mechanisms linking the spread of broadband to fertility change. Related empirical studies have focused on the effect of the Internet on marriage rates (Bellou 2015), teenage fertility (Guldi and Herbst 2017), and the labour force participation of married women (Dettling 2017) in the United States (US). Our contribution to the literature is therefore threefold. First, to the best of our knowledge, this is the first paper to assess the impact of broadband on fertility comprehensively for women and men of all ages. Examining the heterogeneity of the effects across age and education groups enables us to provide further insights on the mechanisms. Second, in contrast to previous studies (e.g., Guldi and Herbst 2017), we use a novel instrumental variable (IV) strategy that allows us to investigate the causal effects of broadband technology on fertility. Third, we focus on a very different context. While other studies focus on the US, this paper analyses Germany, a country where total fertility had previously fallen well below replacement level, dipping as low as 1.2 , but had stabilized around 1.35 by the late 2000s (Haub 2012).

In our analyses, we use data from the German Socio-Economic Panel (SOEP), a longitudinal panel data set about the German population, containing information on a rich set of individual socioeconomic characteristics. These data are uniquely suited for the purpose of studying the effect of broadband diffusion on fertility. First, they contain retrospective life course information, including fertility histories. This information is used to construct our fertility outcomes and, for this reason, the SOEP has been used in a number of studies on fertility in Germany (Hank 2002; Hank and Kreyenfeld 2003; Hofmann and Hohmeyer 2013; Ziefle and Gangl 2014; Bremhorst et al. 2016). Second, our data not only contain household information on whether Internet access is available, but also on whether access is based on a broadband (digital subscriber line, DSL) technology. This information is exploited to build our key explanatory variable. Lastly, the SOEP also contains rich information on individuals' life courses and conditions, including working from home, other labour market behaviour, time spent on childcare, and life satisfaction; thereby enabling us to shed light on the potential mechanisms through which high-speed Internet access may affect fertility. However, the identification of a causal effect of broadband use is complicated by endogeneity concerns. Access to high-speed Internet is likely to be correlated with many unobservable determinants of fertility (e.g., unobserved socioeconomic determinants of fertility, regional characteristics, and differences in timing preferences), which may confound the main relationship of interest, that is, whether the diffusion of high-speed Internet technology is affecting fertility. To address these concerns regarding the endogeneity caused by omitted variables, we follow the strategy adopted by Falck et al. (2014): employing an IV approach that exploits the unique historical and technological peculiarities of the public telephone infrastructure across Germany. These peculiarities have produced large and plausibly exogenous variation in the diffusion of DSL technology throughout the country.

An additional source of concern is reverse causality. It is possible that parenthood leads individuals to seek DSL connection, rather than vice versa. This concern may arise if we look at the contemporaneous effect of DSL access on fertility. However, because our instrument predates the observed fertility behaviour and because we use the longitudinal dimension of our sample to analyse the impact of DSL access on subsequent fertility outcomes, we can rule out reverse causality issues.

We find that DSL access increases the fertility of women aged 25-45. These results are entirely driven by highly educated women. Our findings suggest that the increase in fertility mostly reflects an increase in the probability of progressing to a second or higher-order child. Our two-stage least squares (2SLS) estimates should be interpreted as local average treatment effects (LATEs) and, throughout the paper, we document the substantial heterogeneity in the effects by education and age. We further confirm the results for fertility using 
aggregated data at the county level. Specifically, we find that a one standard deviation increase in DSL availability raises total fertility by approximately 23 per cent. Unsurprisingly, the aggregate estimates are significantly smaller, since we do not explore the heterogeneity in the effects by education and age.

Reassuringly, our results are robust to a large number of sensitivity checks. In the second part of our analysis, we exploit the breadth of our survey data to explore the potential mechanisms underlying these findings. In particular, we show that DSL availability increases the likelihood of teleworking, promotes part-time working, and increases time spent on childcare by highly educated women. Consistent with our 'engine of liberation' hypothesis, that is, that these effects may relax the work-family tradeoff, we also find positive impacts on life satisfaction for highly educated women.

The remainder of this paper is organized as follows. The next section provides the theoretical and empirical background and the main hypotheses of our study. The 'Data' section presents a description of the context and the data we use. The 'Empirical method' section discusses the identification strategy and empirical model. The next section reports the main results of the paper and also includes the county-level analysis and a set of robustness checks. The potential mechanisms linking broadband access with fertility are discussed in the penultimate section, followed by the 'Conclusion' where we discuss the implications of our findings.

\section{Does the Internet matter for fertility? Background and main mechanisms}

An extensive social science literature has analysed the determinants of fertility decisions in low-fertility settings (Morgan and Taylor 2006; Balbo et al. 2013). As a pervasive innovation that affects all realms of society, the Internet is likely to affect several behaviours. How could the Internet in general, and broadband more specifically, possibly affect fertility? Taking into account the relevant literature, we now discuss three potential mechanisms through which this effect could take place, and the implications for testing the relationship empirically, once a plausible causal link has been established.

First, the Internet provides access to unprecedented information about contraceptive behaviours and about the possible life course consequences of the choice to become (or not become) a parent. In contrast to traditional one-directional media, the Internet may enforce social interaction processes that have been seen as important channels in shaping fertility decisions through social learning, social influence, or both (Bongaarts and Watkins 1996; Kohler 2001; Kohler et al. 2001; Bernardi et al. 2007; Balbo and Barban 2014). In addition to research on higher-fertility settings (La Ferrara et al. 2012), there have been contributions highlighting the role of traditional media in shaping teenage fertility in lower-fertility settings. Kearney and Levine (2015) studied the MTV franchise 16 and Pregnant, a series of reality TV shows also including the Teen Mom sequel, which follows the lives of pregnant teenagers in the US during the end of their pregnancies and early days of motherhood. They investigated whether the show influenced teenagers' interest in contraceptive use or abortion, and whether it ultimately altered teenage childbearing outcomes. They found that 16 and Pregnant led to more Google searches and Twitter tweets regarding birth control and abortion, and ultimately led to a 5.7 per cent reduction in teenage births in the 18 months following its introduction. This accounted for around one-third of the overall decline in teenage births in the US during that period. While these results are in accordance with the findings of Trudeau (2016), they have been challenged in a replication study by Jaeger et al. (2016). Directly relevant to this paper are the findings of Guldi and Herbst (2017), who studied the effects of broadband roll-out on US teenage fertility decisions and focused on understanding how broadband diffusion contributed to the observed decline in teenage birth rates, by changing the size of the dating market and increasing the information available to participants. Furthermore, the Internet may increase the quality and quantity of information available on childcare costs and benefits, as well as on health and sexual practices. With regard to the social learning mechanism, it is important to take into account the existence of a 'digital divide' in the ability to extract information from the Internet by educational level (Hargittai 2010).

We can therefore put forward a first hypothesis, in line with Guldi and Herbst (2017), that the Internet has a fertility-decreasing impact at younger ages through this information mechanism. As a caveat, we might take into account that in the setting we study, Germany, teenage pregnancy rates are among the lowest in the world (Sedgh et al. 2015). This 'decreasing' effect may be reversed at older ages, if information seeking and social learning are tied to the proactive achievement of higher desired fertility at later ages. One of the features of the hypothesis linked to information seeking is that Internet access per se is more relevant than access to broadband. 
Second, the Internet may affect the transition to marriage, and more generally, the likelihood of finding a partner to become the parent of a joint child (Rosenfeld and Thomas 2012). As noted by Bellou (2015), the Internet may decrease search costs and increase the rate of partnership offers. The arrival of the Internet has partly displaced traditional pathways of partnership formation, such as family and school, but also partly displaced other pathways such as neighbourhoods, workplaces, and friendship networks (Rosenfeld and Thomas 2012). However, the net impact on marriage and the total indirect impact on fertility may be ambiguous, as the larger pool may at the same time increase the likelihood of a match but increase the desired reservation quality of the searcher with respect to potential partners. The Internet may also crowd out time spent with a partner (or searching for a partner) and thus have negative effects on fertility.

In accordance with this second mechanism, we put forward the second hypothesis: that the effect of the Internet on fertility can be mediated via marriage.

Third, high-speed Internet may affect labour force participation and work-family balance (Wajcman 2015; Dettling 2017), thereby allowing individuals to reconcile work and parenthood more easily. Some recent research has highlighted the roles of home production technology and medical progress (Goldin and Katz 2002; Greenwood et al. 2005; Albanesi and Olivetti 2016) in facilitating the balance between women's labour force participation and fertility choices. Similarly, access to high-speed Internet can relax time constraints, helping individuals to reconcile work and parenthood. By allowing individuals to work remotely, access to high-speed Internet can reduce commuting times, reduce absenteeism, and increase productivity. More importantly for our purposes, it can also reduce childcare costs and allow individuals to spend more time with their families, reducing the non-pecuniary costs of working. Dettling (2017) found that high-speed Internet use led to a 4.1 percentage point increase in labour force participation for married women. Her findings suggest that Internet use for teleworking and for saving time in home production explains the increase in labour force participation. This can be seen as particularly relevant for highly educated individuals, who can potentially work in occupations where telework is possible. It also relies on broadband, rather than any Internet access, as it presupposes reliable and stable connections. Moreover, it might be more relevant for women in their $30 \mathrm{~s}$, as they are under more pressure in terms of workfamily balance than men, being in their 'rush hour of life' (Bittman and Wajcman 2000; Buber-Ennser et al. 2013). With regard to this latter mechanism, Germany represents an interesting case study, since compared with other European countries, the proportion of individuals working from home remains low (Brenke 2016).

For this third mechanism, we put forward the hypothesis that access to broadband is positively related to fertility. We expect this effect to be present in particular for highly educated individuals, for women, and for those at higher reproductive ages. Furthermore, we expect that if the mechanism underlying the positive relationship between broadband and fertility is the facilitation of the work-family balance, then broadband may have limited effects on the decision of whether to have children or not ('extensive margin') but larger effects on the probability of having a second or higher-order child ('intensive margin').

\section{Data}

We draw our data from the SOEP, a household panel survey containing information on approximately 12,000 households and more than 20,000 individuals. It started in West Germany in 1984 and since German reunification in 1990 has also covered East Germany. Each household member above the age of 16 is asked questions annually. The SOEP consists of several subsamples and is constructed to ensure it is representative of the entire population of Germany. A unique feature of this data source lies in its wide range of information at the individual and household levels, including socio-economic characteristics, labour market outcomes, and healthrelated measures. For a detailed description of the survey, see Wagner et al. (2007).

A number of features of the SOEP data make them particularly attractive for the present analysis. First, they contain retrospective information on many dimensions of the life histories of respondents, including fertility histories. We use this information to create our main outcome of interest: the probability of a child being born in a given year.

Second, our data set provides information on Internet access. Of particular importance for our study is the fact that the 2008 SOEP wave, for the first time, provides not only household information on whether Internet access is available, but also on whether Internet access is based on a DSL technology. The availability of such information is essential because it allows for the analysis of the effects of high-speed Internet. Therefore, our key explanatory variable is a dummy variable that indicates whether a household 
has a DSL connection. Our IV strategy is based on the distance of a household residence from the main distribution frame (MDF). To calculate each household's distance to the actual MDF in Germany, we use the exact geo-coordinates of the SOEP households. Access to the geo-coordinate SOEP data is available only on-site at the German Institute for Economic Research (known as the DIW) in Berlin.

Third, our data set contains information on individuals' labour market behaviour, such as whether they work from home, as well as how many hours they spend on childcare during a normal weekday/ Saturday/Sunday, their life satisfaction, and their marital histories. Since we expect that the diffusion of DSL technology will improve work-family balance, these variables enable us to shed some light on the potential mechanisms through which broadband use affects fertility. In particular, our indicator of working from home is a dummy variable, taking a value of ' 1 ' if the individual reports any work from home, or ' 0 ' otherwise. We analyse employment status by constructing three binary variables that indicate whether the individual: (i) works full-time; (ii) works part-time; or (iii) is not working at the time of the interview. We also examine the relationship between broadband and hours worked. To test the marriage channel hypothesis put forward by Bellou (2015), we exploit information on the year of marriage and build a dummy that takes a value of ' 1 ' if the individual gets married in a given year (or ' 0 ' otherwise). Finally, we construct an indicator variable taking a value of ' 1 ' if the respondent reports a life satisfaction higher than the median (eight out of ten points), or ' 0 ' otherwise, as an indicator of high life satisfaction.

Our working sample is constructed as follows. We consider the survey years 2008-12 and restrict attention to individuals aged 17-45 during the years in which outcomes were measured. Moreover, we constrain the analysis to observations with non-missing data on fertility, DSL access, and our main covariates. After these restrictions, we obtain a final longitudinal sample containing 34,495 person-year observations resulting from 17,467 individuals. For the purpose of our analysis, approximately 82 per cent of the sample have complete (non-missing) data. Table 1 reports descriptive statistics on the main variables used in the analysis. About 7 per cent of individuals in the sample report a birth in a given year. Approximately 21 per cent of individuals are working from home. The majority of people are working full-time, although about 26 per cent are not working at all. On average, individuals spend about 3.3 hours on childcare per weekday and 5.4 hours at weekends.
The average individual is 34 years old and about 82 per cent of sample members have a DSL subscription at home. Approximately 33 per cent have received higher secondary school education (academic track or Abitur) and close to 34 per cent have obtained an intermediate secondary education certificate (intermediate track or Realschulabschluss). It is worth mentioning that the German secondary school system is traditionally structured as a tracked system; a detailed description of the German school system can be found in Jonen and Eckardt (2006).

Throughout the paper, we define as 'highly educated' those individuals with higher (academic) or intermediate secondary education. We define as 'less educated' those individuals in the residual category, which includes individuals with lower secondary education (basic track or Hauptschulabschluss), as well as individuals who left school without this certificate or are still in school. However, the results remain intact if only those individuals with lower secondary education are included.

In Figures 1 and 2, we analyse age differences in fertility behaviour among highly educated and lesseducated individuals, respectively. Overall, the pattern that emerges is that broadband access at home is positively correlated with the probability of a birth, but only among highly educated individuals aged 26 and above. Interestingly, the opposite pattern is seen among less-educated individuals. However, it is not clear whether the positive correlation for the highly educated is driven by selection on unobservable factors or whether it is capturing a causal effect. In what follows, we use an IV identification strategy to investigate whether DSL availability has causally increased fertility.

Figure 3 reports the share of SOEP households with access to DSL for the survey years 2008, 2010, and 2012 across German counties (Kreise and kreisfreie Städte). As can be seen, the proportion of households with DSL access increases sharply over this period. Similarly, Figure 4 documents total fertility across Germany over the same period.

\section{Empirical method}

\section{Model specification}

Our main working model is an annual linear probability model for childbirth:

$$
\begin{aligned}
Y_{i s t}= & \alpha+\beta D S L_{i s t}+\gamma X_{i s t}+\mu_{t}+\eta_{s}+\lambda^{1} t \\
& +\varepsilon_{i s t}
\end{aligned}
$$


Table 1 Descriptive statistics for SOEP sample, Germany 2008-12 ( $n=34,495$ person-years)

\begin{tabular}{|c|c|c|c|c|}
\hline & $\begin{array}{c}(1) \\
\text { Mean/proportion }\end{array}$ & $\begin{array}{c}(2) \\
\text { Standard deviation }\end{array}$ & $\begin{array}{l}(3) \\
\text { Minimum }\end{array}$ & $\begin{array}{c}(4) \\
\text { Maximum }\end{array}$ \\
\hline \multicolumn{5}{|l|}{ Outcome variables } \\
\hline Birth in current year & 0.065 & 0.247 & 0 & 1 \\
\hline Working from home & 0.208 & 0.406 & 0 & 1 \\
\hline Part-time work & 0.313 & 0.464 & 0 & 1 \\
\hline Full-time work & 0.431 & 0.495 & 0 & 1 \\
\hline Working hours (weekly) & 32.064 & 14.804 & 0 & 60 \\
\hline Not working & 0.256 & 0.437 & 0 & 1 \\
\hline Hours spent on childcare (weekdays) & 3.276 & 4.994 & 0 & 24 \\
\hline Hours spent on childcare (weekends) & 5.358 & 6.134 & 0 & 24 \\
\hline Life satisfaction & 7.303 & 1.646 & 0 & 10 \\
\hline High life satisfaction & 0.207 & 0.405 & 0 & 1 \\
\hline Got married in current year & 0.024 & 0.154 & 0 & 1 \\
\hline \multicolumn{5}{|l|}{ Broadband $^{1}$} \\
\hline DSL subscription in household & 0.815 & 0.388 & 0 & 1 \\
\hline Threshold dummy & 0.111 & 0.314 & 0 & 1 \\
\hline 'No closer MDF' dummy & 0.942 & 0.233 & 0 & 1 \\
\hline OPAL dummy & 0.010 & 0.101 & 0 & 1 \\
\hline \multicolumn{5}{|l|}{ Control variables } \\
\hline Female & 0.553 & 0.497 & 0 & 1 \\
\hline Age & 33.763 & 8.031 & 17 & 45 \\
\hline Married & 0.538 & 0.499 & 0 & 1 \\
\hline Single & 0.398 & 0.490 & 0 & 1 \\
\hline Divorced & 0.060 & 0.237 & 0 & 1 \\
\hline Number of children & 1.234 & 1.166 & 0 & 11 \\
\hline Rural area & 0.361 & 0.480 & 0 & 1 \\
\hline West Germany & 0.820 & 0.384 & 0 & 1 \\
\hline Lower secondary education (basic track) & 0.199 & 0.399 & 0 & 1 \\
\hline Medium secondary education (intermediate track) & 0.344 & 0.475 & 0 & 1 \\
\hline Higher secondary education (academic track) & 0.325 & 0.469 & 0 & 1 \\
\hline Apprentice & 0.127 & 0.333 & 0 & 1 \\
\hline Unemployed & 0.073 & 0.260 & 0 & 1 \\
\hline Blue-collar worker & 0.222 & 0.416 & 0 & 1 \\
\hline White-collar worker & 0.400 & 0.490 & 0 & 1 \\
\hline Entrepreneur & 0.058 & 0.234 & 0 & 1 \\
\hline First-generation immigrant & 0.130 & 0.336 & 0 & 1 \\
\hline Second-generation immigrant & 0.109 & 0.312 & 0 & 1 \\
\hline Household income (log) & 7.861 & 0.546 & 0 & 11.408 \\
\hline
\end{tabular}

${ }^{1}$ See 'Empirical method' section for details of broadband variables.

Notes: Data are for individuals aged 17-45 years. All the samples contain individuals for whom information on childbirth in current year, all observables, and the respective outcome variable are non-missing. The sample sizes for working from home, working hours, childcare (weekdays), childcare (weekends), and life satisfaction are, respectively: 11,590; 24,559; 33,273; 10,802; and 34,169 person-years. Source: Authors' analysis of SOEP (v32).

where the index ist denotes an individual $i$, residing in state $s$ at the year of interview $t$. The outcome variable $Y_{i s t}$ represents the probability of a birth to individual $i$.

Our variable of interest is $D S L_{i s t}$, defined as a dummy variable taking the value ' 1 ' if the individual has a DSL subscription, or ' 0 ' otherwise. Thus, the treatment effect, $\beta$, denotes whether fertility increases for individuals with a DSL subscription. The model contains survey year fixed effects $\left(\mu_{t}\right)$ to account for possible trends in fertility behaviour. We also include a full set of federal state fixed effects $\left(\eta_{s}\right)$, to control for unobservable, time-invariant differences across states (Länder) that may influence fertility, as well as a set of linear statespecific time trends $\left(\lambda^{1} t\right)$ that control for unobserved cross-state differences in fertility over time. The vector of individual covariates that may affect fertility is denoted by $X_{i s t}$. Specifically, we include sex, age and age squared, a set of secondary school track effects (basic, intermediate, or academic track), indicators for marital status, occupational status, and migration background, a dummy for urban status, and the logarithm of net 


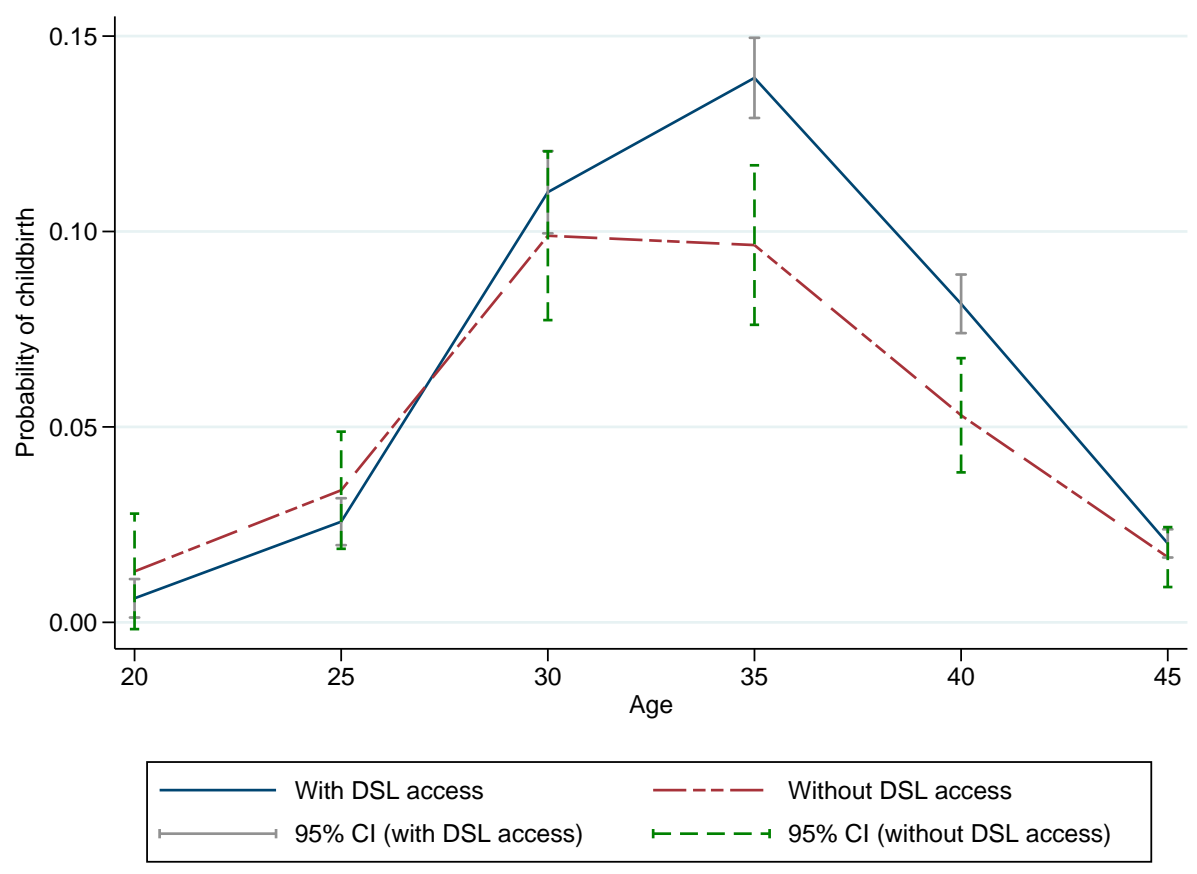

Figure 1 Annual probability of childbirth by DSL access and age: highly educated individuals, Germany 2008-12 Source: Authors' analysis of SOEP data.

household income. Finally, $\varepsilon_{i s t}$ represents a disturbance term.

The need for an identification strategy arises from the potential correlation of high-speed Internet with various unobservable determinants of fertility (including, e.g., unobserved socio-economic factors, regional characteristics, and heterogeneity in timing preferences). Such correlation may confound our relationship of interest. For example, one obvious concern is that richer and better educated households may be more willing to pay for a DSL subscription at home, and that this may induce telecommunication carriers to deploy DSL infrastructure strategically in areas with higher average income. Moreover, richer individuals may be systematically different from the rest of the population in terms of their fertility behaviour. While we are able to control for a large set of observed background characteristics to address this concern, there may still be unobserved confounders, which would bias our estimates of $\beta$. To circumvent this endogeneity concern caused by omitted variables, we use an IV identification strategy based on the geography and history of the layout of the pre-existing telephone infrastructure across Germany, as detailed in the next subsection.

One additional potential source of concern is reverse causality. Families with young children may seek DSL access to reconcile parenthood and work. However, this concern is mitigated by the fact that we rely on an instrument that predates the fertility behaviour under study and also the fact that we exploit the longitudinal dimension of the data to analyse the impact of DSL availability on subsequent fertility outcomes over the period 2008-12.

\section{Identification strategy}

To address the concern regarding endogeneity of broadband use, we follow the identification strategy adopted by Falck et al. (2014) to study the effects of DSL access on voting behaviour. Their main idea was to exploit the historical variation in preexisting telephone infrastructure that significantly affected the cost of broadband adoption across Germany. In particular, they exploited three unique historical and technological peculiarities of the traditional public telephone network that influenced the deployment of DSL in German municipalities (Gemeinden). Falck et al. (2014) provide a detailed description of the variation in the diffusion of DSL technology across municipalities throughout the country. Importantly, the authors argue that highspeed Internet subscriptions in Germany are almost exclusively based on DSL technology.

A crucial cost factor in enabling DSL connection is the distance between a household and the MDF. For technical reasons, when the distance is larger than approximately $4.2 \mathrm{~km}$, DSL technology becomes substantially costlier unless households can be 


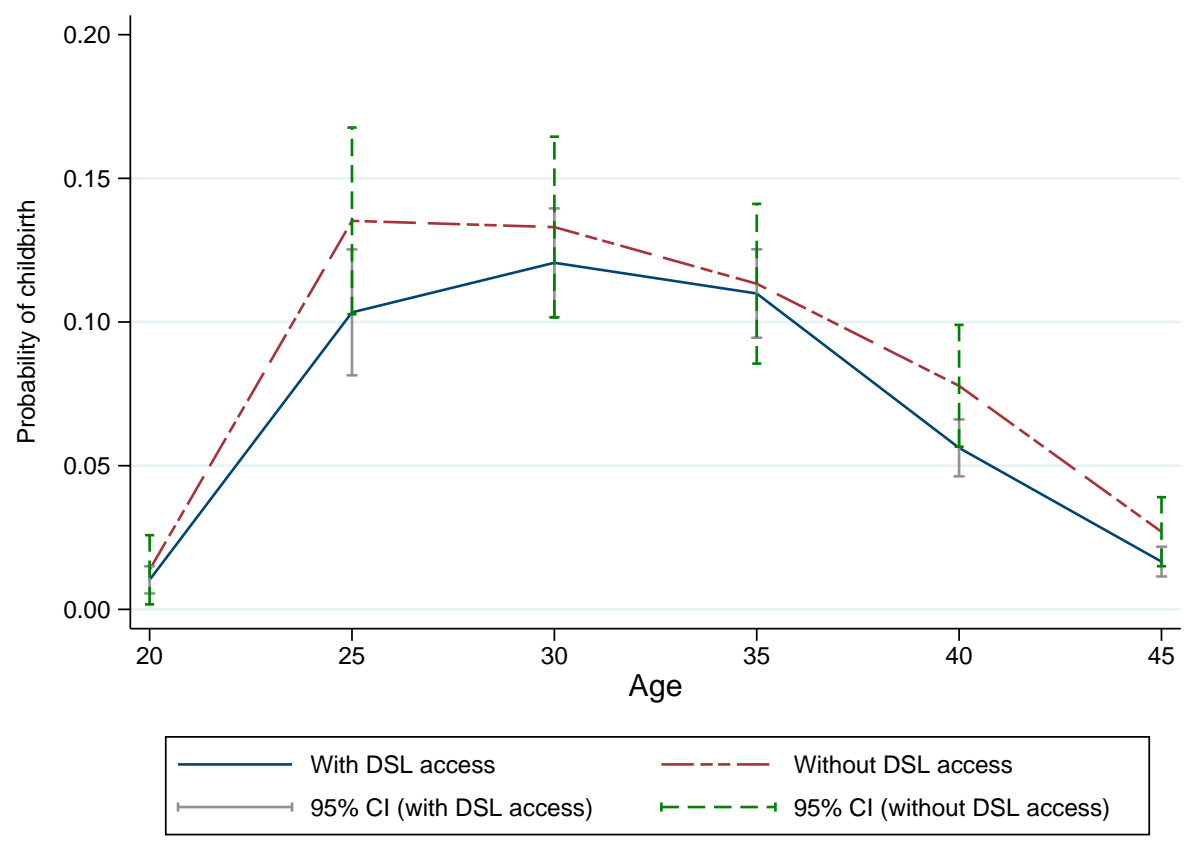

Figure 2 Annual probability of childbirth by DSL access and age: less-educated individuals, Germany 2008-12 Source: As for Figure 1.

connected to an alternative MDF in the close vicinity. While most populated municipalities had their own MDF (as part of the telephone network installed in the 1960s), in less populated areas the presence of the MDF was largely determined by the availability of buildings and lots that could host one of the MDFs. The length of the copper wires was irrelevant for the quality of the telephone services, but it became a crucial determinant of the cost of adoption of DSL, since starting from about $4.2 \mathrm{~km}$ from the MDF, parts of copper wire must be replaced with fibre wire, thereby increasing length of line adaptation and costs. In practice, as the first generation of DSL was built entirely on the pre-existing voice telephone network, which was not designed for the needs of high-speed Internet, one-third of the municipalities in West Germany could not adopt DSL.

As mentioned earlier, to calculate each household's distance to the actual MDF in Germany, we use the exact geo-coordinates of the SOEP households. Using confidential information on the residential addresses of households, we follow Falck et al. (2014) and construct two household-level binary instruments: the first (and main) instrument is equal to ' 1 ' for households with a distance to their MDF above the threshold of $4.2 \mathrm{~km}$, or ' 0 ' otherwise; the second instrument is equal to ' 1 ' for households above the threshold that cannot be connected to another MDF at a distance below $4.2 \mathrm{~km}$. In addition, approximately one-tenth of the East German population could not access DSL because of a technical error in the 1990s in the roll-out of the telecommunication infrastructure (Falck et al. 2014). After reunification, many regions in East Germany lacked a proper telephone network and adopted the optical access line (OPAL) technology, which at the time was the best telephone technology on the market. Therefore, our third instrument indicates whether the respondent resides in an area initially supplied with OPAL technology. Yet, a decade later this technology proved to be incompatible with DSL technologies, thereby implying substantially higher costs for DSL connection in these areas.

In this paper, we rely on these historical peculiarities, which affected the deployment of firstgeneration DSL and significantly influenced the cost of the telecommunication infrastructure rollout. These three instruments provide us with plausibly exogenous variation in DSL availability, which we exploit to identify the causal effects of broadband access on fertility decisions. As in Falck et al. (2014), to construct these three household-level binary instruments we use confidential data on the geo-coordinates of the SOEP households.

Model 1 is estimated using 2SLS regression, and the first-stage regression is given by:

$$
\begin{aligned}
D S L_{i s t}= & \eta+\text { SThreshold }_{i s t} \\
& +\theta(\text { No closer } M D F)_{i s t}+\sigma O P A L_{i s t} \\
& +\rho X_{i s t}+\mu_{t}+\eta_{s}+\lambda^{1} t+v_{i s t}
\end{aligned}
$$

where $D S L_{i s t}$ is instrumented with Threshold $_{i s t}$, an 
(a)

2008

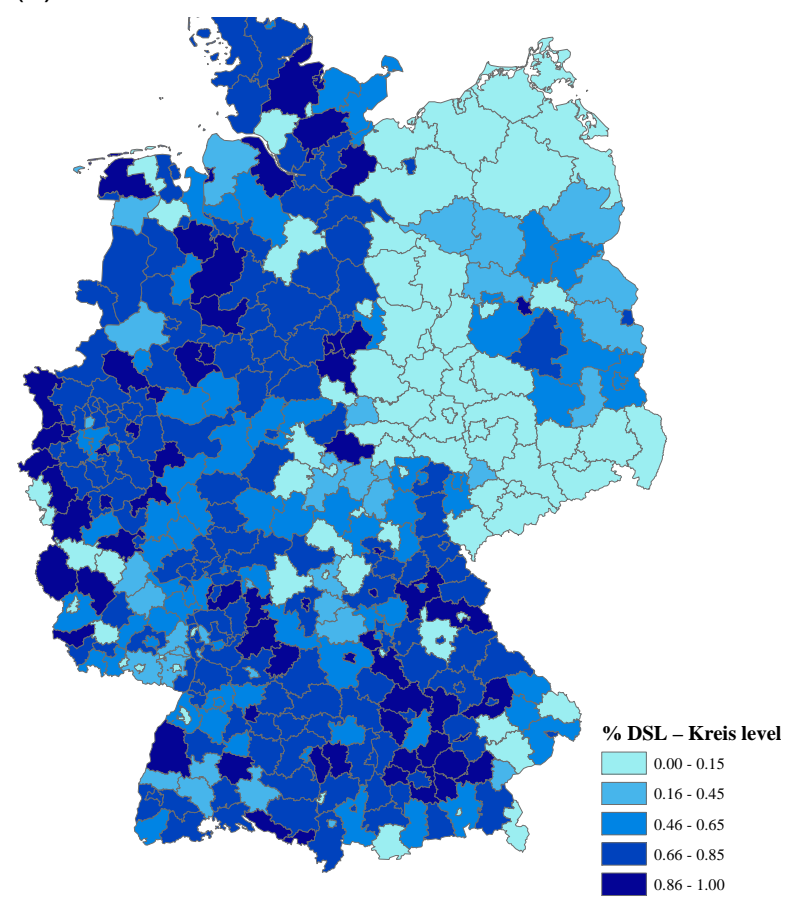

(b)

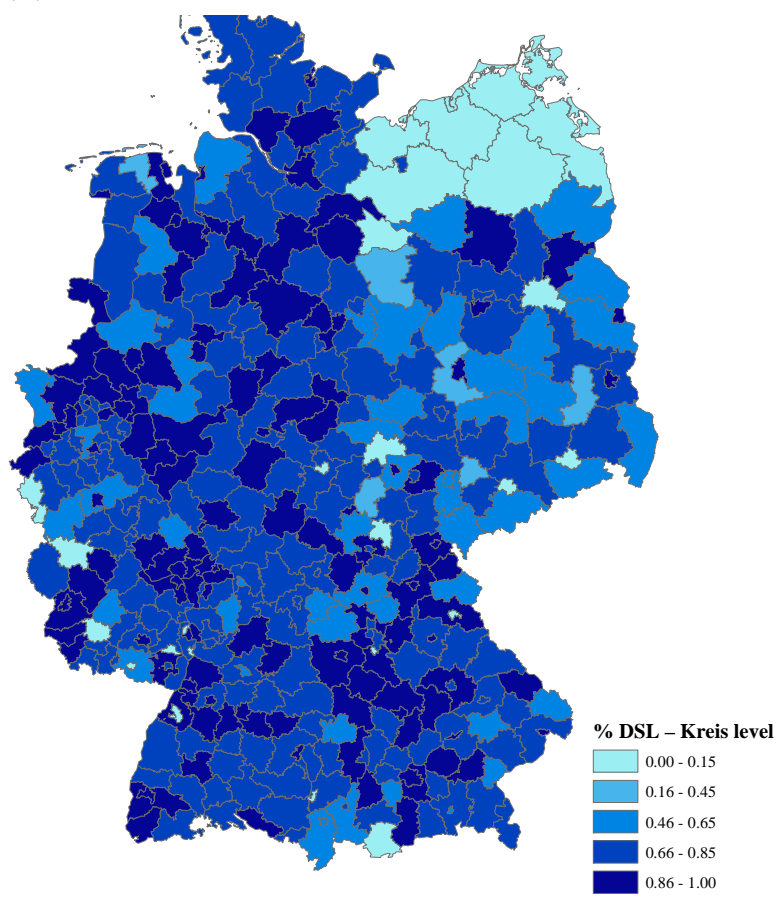

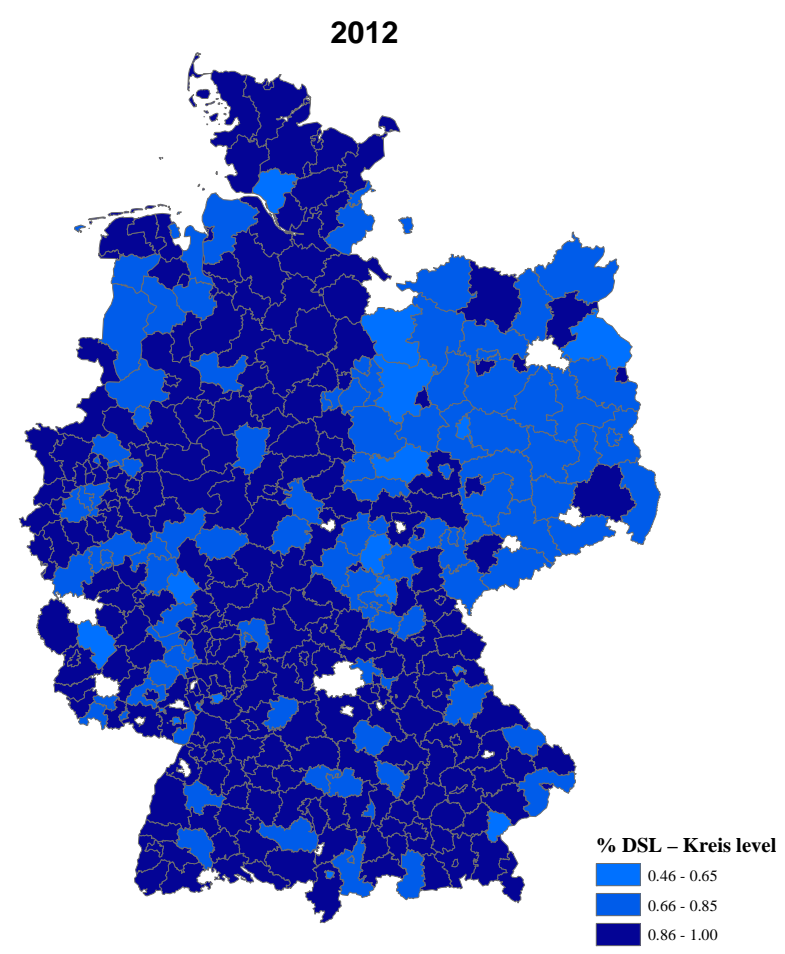

Figure 3 Proportion of SOEP households with DSL access by county (Kreis): Germany 2008, 2010, and 2012 Notes: Darker areas correspond to higher levels of DSL access in the corresponding county (Kreis).

Source: As for Figure 1.

indicator for whether the respondent resides more than $4.2 \mathrm{~km}$ away from their MDF. Similarly, (No closer $M D F)_{\text {ist }}$ is a binary variable identifying those respondents who live more than $4.2 \mathrm{~km}$ away from their MDF, but could be connected to a closer
MDF. Our third instrument is given by $O P A L_{i s t}$, which indicates whether the respondent resides in an area initially supplied with OPAL technology. The variable $X_{i s t}$, the parameters $\mu_{t}, \eta_{s}$, and $\lambda^{1} t$, and the error term $v_{i s t}$ are defined in the same way as in 
(a)

2008

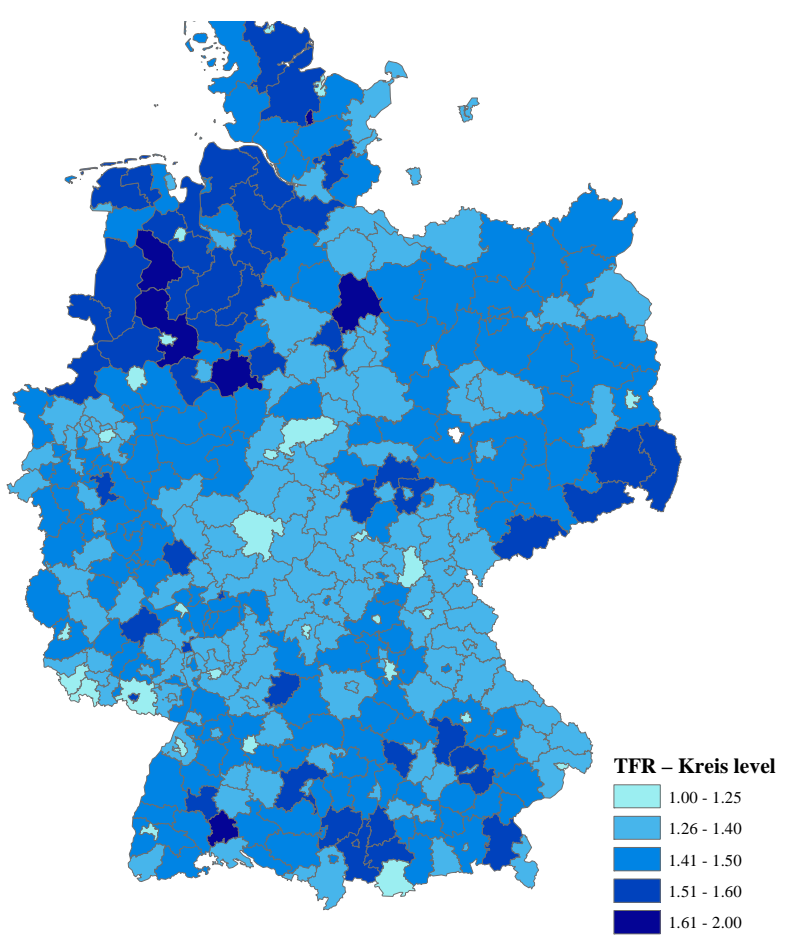

(b)

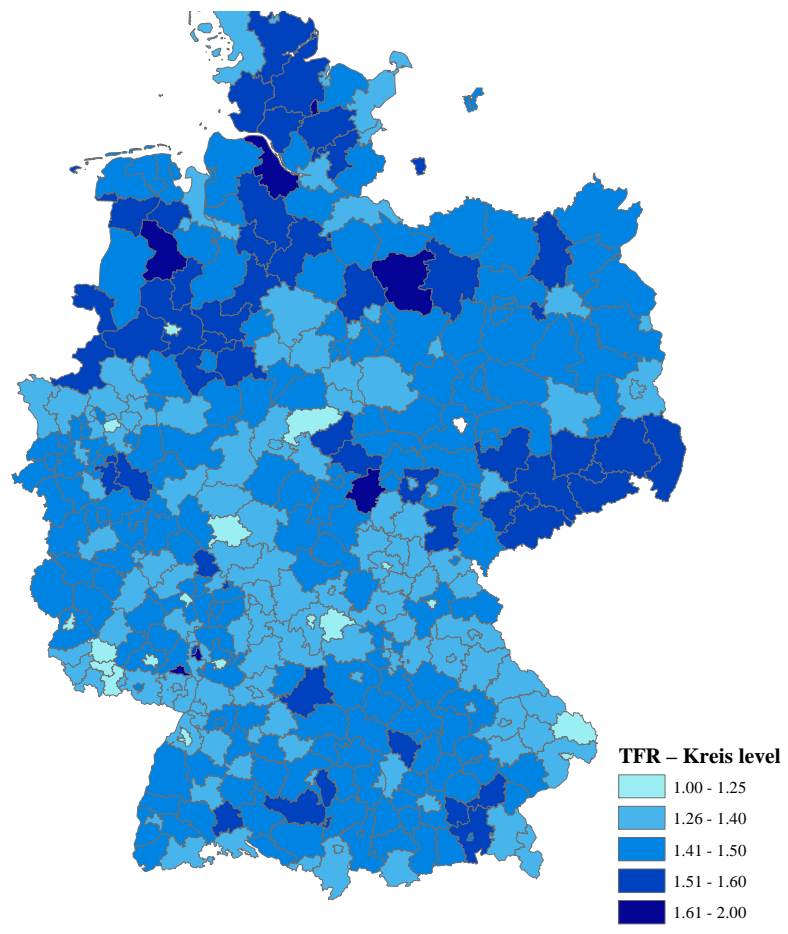

(c)

2012

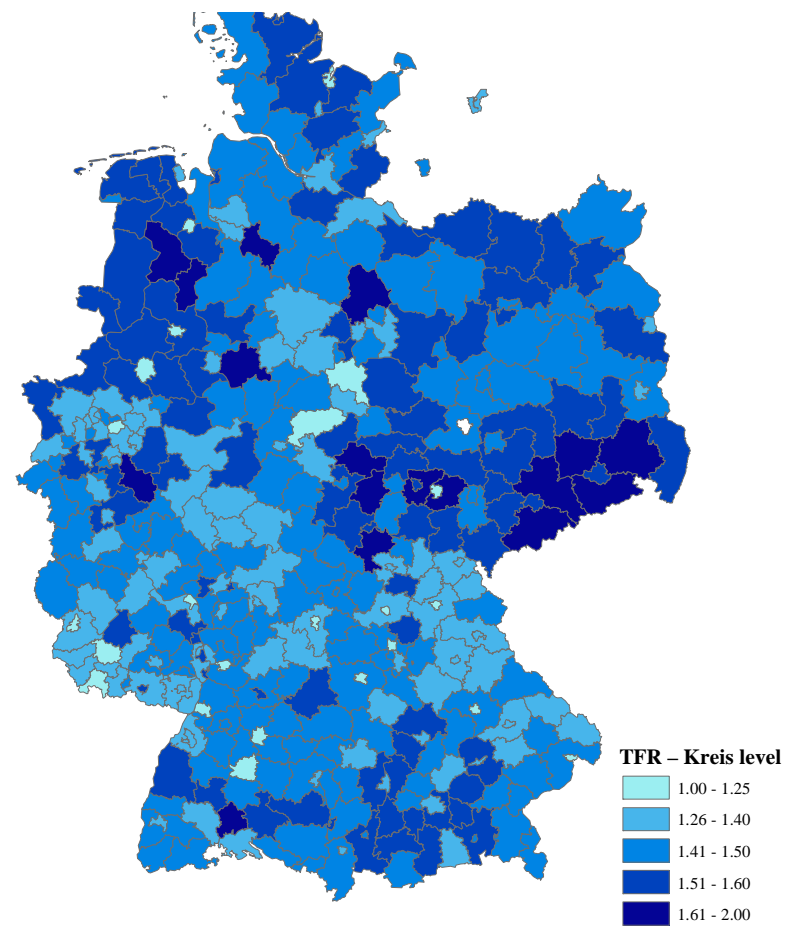

Figure 4 Total fertility by county (Kreis): Germany 2008, 2010, and 2012

Notes: Darker areas correspond to higher levels of fertility in the corresponding county (Kreis).

Source: INKAR administrative records. 
equation (1). Throughout the analysis, we cluster standard errors by household, the level of variation of our instruments. All the results are robust to clustering at the municipality or county level (see Tables A18-A21 in the supplementary material). We further address this issue in the 'Robustness' subsection. Note that Tables A1-A27 can all be found in the supplementary material.

\section{Results}

\section{Main results}

Table 2 reports the estimates of the effects of DSL access on fertility based on the identification strategy previously described. Columns (1)-(3) display the results for the sample of individuals aged $17-45$ by sex, whereas columns (4)-(6) and (7)-(9) report the estimates obtained by dividing the sample into two groups: individuals aged 17-24 and those aged 2545 , respectively. In addition, the lower part of Table 2 presents the corresponding results from the first-stage regression. As described in the previous section, in each regression we include a set of individual controls, survey year and state fixed effects, and state-specific time trends.

The first-stage results show that our three instruments are all negatively related to DSL availability and that, considering the samples of individuals aged 17-45 and 25-45, the $F$-statistic of excluded instruments ranges from 14.43 to 24.43 , values above the conventional levels (Stock and Yogo 2002). Moreover, the overidentification test statistics for each of the models reported in Table 2 are far from critical values at conventional significance levels, thereby providing support that the three instruments are jointly valid instruments.

We now move to the examination of the 2SLS results (upper part of Table 2). The 2SLS estimates are much larger than the ordinary least squares (OLS) estimates shown in Table A1, which are positive but significantly smaller and statistically non-significant for individuals aged 25-45, suggesting a negative correlation between unobservable determinants of fertility and access to DSL. Another plausible explanation for the fact that the OLS estimates are much smaller is that our instruments do not affect the entire population across local areas; that is, our identification strategy allows us to recover only a LATE rather than an average treatment effect (ATE) across the population.

There are important sex differences. When examining the sample as a whole (column (1)), we find that the coefficient for DSL access is positive but not significantly different from zero. Interestingly, these average effects mask heterogeneous effects by sex and age. The effect is significant among women (column (2)), while among men the point estimate is positive but much smaller (column (3)).

It is worth noting that the result for men may reflect the fact that we restrict the sample to individuals aged up to 45 . This restriction is dictated by our focus on women's fertility behaviour, yet notably men tend to become parents at an older age than women. Furthermore, men are less likely to respond to the survey questions on biological children that we use to construct our main fertility outcome. This also reduces the sample size and may explain the loss of precision in the estimates. However, it is worth noting that, in most instances, the point estimate of the effect of DSL access on men's fertility is not statistically different from the one estimated for women.

Furthermore, columns (4)-(6) show no evidence of significant impacts among individuals aged 17-24. When considering those aged 25-45, the coefficient for DSL access becomes positive, with a statistically significant effect (at the 5 per cent level) for women (column (8)). For the latter group, access to highspeed Internet implies an increase in the probability of a birth of 11.3 percentage points. Again, it is worth remarking that these estimates are LATEs rather than ATEs. Furthermore, standard errors are large and, thus, despite the significant difference in the size of the coefficients, the confidence intervals of the OLS and 2SLS estimates overlap. These effects are consistent with the idea that relatively older women may be more responsive to the increase in work flexibility associated with the possibility of working from home or working part-time. Again, there is no evidence of significant effects for men (column (9)).

Overall, Table 2 suggests the presence of heterogeneous effects by age group and sex, with the fertility behaviour of women aged 25-45 being significantly affected by DSL access at home. We would expect these effects to be larger among highly educated women. We note, however, that given the large standard errors and the relative weakness of the IV approach, the magnitude of the 2SLS estimates should be interpreted with caution.

To investigate these differential effects further, Table 3 provides the 2SLS estimation results by education group for individuals aged 25-45. The overidentification test statistics for each of the models in Table 3 shows, once again, that we fail to reject the hypothesis that the three instruments are jointly 
Table 2 Effects of access to broadband on fertility by age group and sex, Germany 2008-12

\begin{tabular}{|c|c|c|c|c|c|c|c|c|c|}
\hline \multirow[b]{2}{*}{ Age group and sex: } & $(1)$ & $\begin{array}{c}(2) \\
17-45\end{array}$ & (3) & \multicolumn{3}{|c|}{$17-24$} & \multicolumn{3}{|c|}{$25-45$} \\
\hline & All & Women & Men & All & Women & Men & All & Women & Men \\
\hline \multicolumn{10}{|l|}{ Dependent variable: birth in current year } \\
\hline DSL subscription & $\begin{array}{c}0.071 \\
(0.046)\end{array}$ & $\begin{array}{l}0.105^{* *} \\
(0.049)\end{array}$ & $\begin{array}{c}0.041 \\
(0.050)\end{array}$ & $\begin{array}{c}0.021 \\
(0.051)\end{array}$ & $\begin{array}{c}0.003 \\
(0.083)\end{array}$ & $\begin{array}{c}0.046 \\
(0.039)\end{array}$ & $\begin{array}{c}0.080 \\
(0.055)\end{array}$ & $\begin{array}{l}0.113 * * \\
(0.055)\end{array}$ & $\begin{array}{c}0.044 \\
(0.064)\end{array}$ \\
\hline Mean of dependent variable & 0.065 & 0.065 & 0.066 & 0.028 & 0.041 & 0.015 & 0.073 & 0.069 & 0.078 \\
\hline Standard deviation of dependent variable & 0.247 & 0.246 & 0.248 & 0.165 & 0.198 & 0.121 & 0.260 & 0.254 & 0.268 \\
\hline \multicolumn{10}{|l|}{ First stage ${ }^{1}$} \\
\hline Threshold & $\begin{array}{c}-0.132 * * * \\
(0.018)\end{array}$ & $\begin{array}{l}-0.124 * * * \\
(0.020)\end{array}$ & $\begin{array}{l}-0.142 * * * \\
(0.023)\end{array}$ & $\begin{array}{c}-0.163 * * * \\
(0.039)\end{array}$ & $\begin{array}{l}-0.142 * * * \\
(0.049)\end{array}$ & $\begin{array}{l}-0.187 * * * \\
(0.054)\end{array}$ & $\begin{array}{c}-0.127^{* * * *} \\
(0.019)\end{array}$ & $\begin{array}{c}-0.122 * * * \\
(0.020)\end{array}$ & $\begin{array}{c}-0.131 * * * \\
(0.024)\end{array}$ \\
\hline 'No closer MDF' & $\begin{array}{c}-0.062 * * \\
(0.024)\end{array}$ & $\begin{array}{c}-0.052 * * \\
(0.026)\end{array}$ & $\begin{array}{c}-0.074 * * \\
(0.030)\end{array}$ & $\begin{array}{c}-0.104 * * \\
(0.050)\end{array}$ & $\begin{array}{c}-0.096 \\
(0.060)\end{array}$ & $\begin{array}{c}-0.103 \\
(0.069)\end{array}$ & $\begin{array}{c}-0.055^{* *} \\
(0.025)\end{array}$ & $\begin{array}{c}-0.044 * \\
(0.026)\end{array}$ & $\begin{array}{c}-0.067 * * \\
(0.031)\end{array}$ \\
\hline OPAL & $\begin{array}{c}-0.091 * * \\
(0.043)\end{array}$ & $\begin{array}{c}-0.066 \\
(0.047)\end{array}$ & $\begin{array}{c}-0.117^{*} \\
(0.060)\end{array}$ & $\begin{array}{c}-0.085 \\
(0.086)\end{array}$ & $\begin{array}{c}-0.104 \\
(0.095)\end{array}$ & $\begin{array}{c}-0.061 \\
(0.137)\end{array}$ & $\begin{array}{c}-0.091 * * \\
(0.043)\end{array}$ & $\begin{array}{c}-0.058 \\
(0.049)\end{array}$ & $\begin{array}{c}-0.128 * * \\
(0.059)\end{array}$ \\
\hline$F$-test of excluded instruments & 24.43 & 19.00 & 17.73 & 7.074 & 3.842 & 4.901 & 21.71 & 19.04 & 14.43 \\
\hline Overidentification test & 0.895 & 0.861 & 0.494 & 1.083 & 1.243 & 0.541 & 1.328 & 1.039 & 0.793 \\
\hline$\chi^{2} p$-value & 0.639 & 0.650 & 0.781 & 0.582 & 0.537 & 0.763 & 0.515 & 0.595 & 0.673 \\
\hline Observations & 34,495 & 19,069 & 15,426 & 5,988 & 3,036 & 2,952 & 28,507 & 16,033 & 12,474 \\
\hline
\end{tabular}

${ }^{1}$ See 'Empirical method' section for details of broadband variables.

Notes: Standard errors are reported in parentheses and are clustered at the household level. All models include controls for education, age and its quadratic term, sex, an indicator for rural area, marital status, occupational status, migration background, and log of net household income. All regressions further include state and survey year fixed effects, as well as state-specific time trends. The $F$-test for excluded instruments refers to the Kleibergen-Paap $F$-statistic. The overidentification test is based on the Huber-White robust variance-covariance matrix without clustering.

*Significant at 10 per cent; **significant at 5 per cent; ***significant at 1 per cent.

Source: As for Table 1. 
valid instruments. Consistent with our prior, we find a positive effect of DSL on fertility among highly educated women (column (3)). On the contrary, the coefficient is negative and not statistically significant among the less educated. The magnitude of the effect of DSL access for highly educated women is 13.3 percentage points. The treatment effect remains positive (7 percentage points), albeit non-significant, among highly educated men. Since our baseline age interval (17-45) may not be entirely appropriate for describing the fertility behaviour of men, we also extend the sample to males aged up to 55 (Table A2). When including these older men, we find a marginally statistically significant effect for the highly educated (column (2)). Specifically, we find that DSL access increases the probability of a birth by 6.2 percentage points.

The remaining part of the paper will focus only on highly educated women aged 25-45, the group most affected by the availability of high-speed Internet at home. In the supplementary material, we also report the results for highly educated women in various age brackets: $25-29,30-34,35-39$, and 4045. Overall, the results appear to be driven by women in their 30s (see columns (3) and (4) in Table A3). Results go in the same direction if we use an interaction model: we continue to find that the effects are mostly concentrated among highly educated women in their late 30s. We report the corresponding OLS estimates for highly educated women and men in Table A4.

Moreover, we find that our main results are driven by the decision to have a second or higher-order child (Table A5) rather than the decision to have a first child, suggesting that while Internet access does not affect fertility choice on the extensive margin, it has significant effects on the intensive margin.

\section{County-level analysis}

Table 4 shows our estimates of the effects of highspeed Internet on fertility using aggregated data at county level. While one of the major advantages of using aggregated data is that they cover the entire country, the main drawback is that they do not allow us to explore the heterogeneity of the effects by age and education group.

The INKAR (Indikatoren und Karten zur Raumentwicklung) data set is provided by the German Federal Office for Building and Regional Planning, and contains a wide range of regional economic and demographic figures. From the INKAR administrative records we collected county-level information on economic characteristics, such as gross domestic product (GDP) per capita and labour market indicators, and on demographic and social characteristics, such as total fertility, population density, the net migration rate, the proportion of individuals with a university degree, and the proportion of individuals of working age (aged 18-64). Counties represent the smallest geographical units for which information on total fertility is provided by the INKAR.

Information on DSL availability - a continuous variable, defined as the share of households that can access DSL in a given year and county-is drawn from the German broadband atlas (Breitbandatlas Deutschland), an annual survey on broadband availability conducted by the German Ministry of Economics and Technology since the year 2005 (Bundesministerium für Wirtschaft und Technologie 2010). Specifically, telecommunication operators self-reported the number of households that were covered by their DSL connections. For more details, see Falck et al. (2014), who used this data set for their analysis with municipality-level data.

We thus rely on a first-difference model, in which we investigate whether the differential introduction of broadband, from 1999 (pre-Internet period) to 2008 (broadband period), is related to changes in total fertility at the county level over the same period. It should be noted that in 1999, broadband was not yet available - and thus, we assume DSL availability in 1999 to be zero-whereas in 2008, DSL availability was in rapid expansion across Germany (Falck et al. 2014). By using first differences, the model eliminates bias from time-invariant unobserved county-level heterogeneity related both to total fertility and to DSL availability.

Using county-level data, we confirm the positive relationship between broadband availability and fertility, as displayed in Table 4. The point estimates of the coefficient of interest are considerably smaller (in percentage) compared with those obtained using individual-level data from the SOEP. In particular, the OLS estimate reported in column (1) suggests that a one standard deviation increase in DSL availability is associated with an increase in total fertility of about 5 per cent relative to average total fertility. The coefficient is significant and robust to the inclusion of the county-level contextual variables (column (2)).

Following Falck et al. (2014), in the aggregate analysis we used only our main instrument based on distance from the municipality's own MDF. In practice, we first classified municipalities based on whether their centroid was above or below the $4.2 \mathrm{~km}$ threshold from their own MDF. Then, we 
Table 3 Effects of broadband on fertility by education and sex: individuals aged 25-45, Germany 2008-12

\begin{tabular}{|c|c|c|c|c|c|c|}
\hline Sex and education group: & $\begin{array}{c}\text { (1) } \\
\text { All } \\
\text { Highly } \\
\text { educated }\end{array}$ & $\begin{array}{c}\text { (2) } \\
\text { All } \\
\text { Less } \\
\text { educated }\end{array}$ & $\begin{array}{l}\quad(3) \\
\text { Women } \\
\text { Highly } \\
\text { educated }\end{array}$ & $\begin{array}{c}(4) \\
\text { Women } \\
\text { Less } \\
\text { educated }\end{array}$ & $\begin{array}{c}\text { (5) } \\
\text { Men } \\
\text { Highly } \\
\text { educated }\end{array}$ & $\begin{array}{c}\text { (6) } \\
\text { Men } \\
\text { Less } \\
\text { educated }\end{array}$ \\
\hline \multicolumn{7}{|c|}{ Dependent variable: birth in current year } \\
\hline DSL subscription & $\begin{array}{l}0.108^{*} \\
(0.059)\end{array}$ & $\begin{array}{l}-0.032 \\
(0.112)\end{array}$ & $\begin{array}{l}0.133 * * \\
(0.062)\end{array}$ & $\begin{array}{c}-0.074 \\
(0.124)\end{array}$ & $\begin{array}{c}0.070 \\
(0.065)\end{array}$ & $\begin{array}{c}0.034 \\
(0.147)\end{array}$ \\
\hline Mean of dependent variable & 0.075 & 0.070 & 0.072 & 0.063 & 0.079 & 0.076 \\
\hline $\begin{array}{l}\text { Standard deviation of } \\
\text { dependent variable }\end{array}$ & 0.263 & 0.255 & 0.258 & 0.244 & 0.269 & 0.265 \\
\hline \multicolumn{7}{|l|}{ First stage $^{1}$} \\
\hline Threshold & $\begin{array}{l}-0.132 * * * \\
(0.021)\end{array}$ & $\begin{array}{l}-0.105 * * * \\
(0.033)\end{array}$ & $\begin{array}{l}-0.124 * * * \\
(0.022)\end{array}$ & $\begin{array}{l}-0.115 * * \\
(0.047)\end{array}$ & $\begin{array}{l}-0.147 * * * \\
(0.030)\end{array}$ & $\begin{array}{l}-0.092 * * \\
(0.037)\end{array}$ \\
\hline 'No closer MDF' & $\begin{array}{l}-0.061 * * \\
(0.028)\end{array}$ & $\begin{array}{c}-0.037 \\
(0.045)\end{array}$ & $\begin{array}{c}-0.044 \\
(0.029)\end{array}$ & $\begin{array}{c}-0.047 \\
(0.057)\end{array}$ & $\begin{array}{l}-0.090 * * \\
(0.037)\end{array}$ & $\begin{array}{c}-0.023 \\
(0.055)\end{array}$ \\
\hline OPAL & $\begin{array}{c}-0.094^{* *} \\
(0.047)\end{array}$ & $\begin{array}{c}-0.105 \\
(0.103)\end{array}$ & $\begin{array}{c}-0.036 \\
(0.051)\end{array}$ & $\begin{array}{c}-0.344^{* *} \\
(0.150)\end{array}$ & $\begin{array}{c}-0.159 * * \\
(0.065)\end{array}$ & $\begin{array}{c}0.016 \\
(0.135)\end{array}$ \\
\hline$F$-test of excluded instruments & 18.52 & 5.049 & 15.52 & 4.948 & 12.08 & 2.826 \\
\hline Overidentification test & 0.497 & 3.530 & 0.677 & 2.173 & 0.111 & 2.141 \\
\hline$\chi^{2} p$-value & 0.780 & 0.171 & 0.713 & 0.337 & 0.946 & 0.343 \\
\hline Observations & 19,818 & 8,689 & 11,710 & 4,323 & 8,108 & 4,366 \\
\hline
\end{tabular}

${ }^{1}$ See 'Empirical method' section for details of broadband variables.

Notes: Standard errors are reported in parentheses and are clustered at the household level. All models include controls for education, age and its quadratic term, sex, an indicator for rural area, marital status, occupational status, migration background, and log of net household income. All regressions further include state and survey year fixed effects, as well as state-specific time trends. The $F$-test for excluded instruments refers to the Kleibergen-Paap $F$-statistic. The overidentification test is based on the Huber-White robust variancecovariance matrix without clustering.

*Significant at 10 per cent; **significant at 5 per cent; ***significant at 1 per cent.

Source: As for Table 1.

aggregated the data at the county level, and used the share of municipalities above the threshold as the instrument. In our county-level analysis, we did not use the other two instruments, since these two measures became very noisy at the county level, given that only a small number of municipalities were above the $4.2 \mathrm{~km}$ threshold from their own
MDF and below the $4.2 \mathrm{~km}$ threshold from another municipality's MDF. Similarly, only a limited number of municipalities had the OPAL technology. Again, aggregating these two instruments at the county level did not leave us with enough variation to exploit (the first-stage $F$-statistics are well below the conventional level).

Table 4 County-level analysis: first-difference model of effects of broadband on fertility, Germany 1999-2008

(1)

Dependent variable: change in TFR

Change in DSL availability 1999-2008

Control variables

Mean of dependent variable

Standard deviation of dependent variable

$F$-test of excluded instrument

Observations
(2)

OLS

$\begin{array}{cc}0.065^{* *} & 0.063^{* *} \\ (0.025) & (0.026) \\ \text { No } & \text { Yes } \\ 1.406 & 1.406 \\ 0.131 & 0.131 \\ - & - \\ 763 & 763\end{array}$

(3)

2SLS

(4)

Notes: Standard errors are reported in parentheses and are clustered at the county level. The dependent variable is the change in the total fertility rate (TFR) at the county level between 1999 and 2008. All regressions include survey year fixed effects. Columns (2) and (4) also include county-level controls, such as GDP per capita, population density, net migration rate, the population share of individuals with a university degree, and the population share of individuals of working age (18-64).

*Significant at 10 per cent; **significant at 5 per cent; ***significant at 1 per cent.

Source: Authors' analysis of INKAR data. 
The 2SLS coefficient presented in column (3) of Table 4 remains positive and statistically significant. Reassuringly, the first-stage $F$-statistic is above 20 . When we add county-level controls to the model (column (4)), we find that a one standard deviation increase in DSL availability will raise total fertility by 23 per cent relative to average total fertility. The magnitude of this effect is about five times larger than the corresponding OLS estimate (column (2)), but again the confidence intervals of the OLS and 2SLS estimates overlap because of the large standard errors of the latter.

Overall, these aggregate-level results confirm the positive effects of high-speed Internet on fertility obtained in the individual-level analysis (Tables 2 and 3). However, the aggregate estimates are significantly smaller than those obtained using individuallevel data. This is not surprising, since we cannot explore the heterogeneity of the effects by education and age, and thus we estimate an effect closer to an ATE.

\section{Robustness}

To assess the robustness of our main results, in Table A6 we report on the sensitivity of our main estimates to the use of different samples or specifications. We focus on our baseline sample: highly educated women aged 25-45.

A possible threat to the validity of our identification strategy arises from the endogenous sorting of families across Germany in response to the better DSL connections available in given areas. In particular, a relevant concern is the reverse causation, which can lead to biased estimates of highspeed Internet. For example, individuals who are planning to have children may seek to locate to areas with better access to high-speed Internet. To check that our results are not driven by potential violations of this no-sorting condition, in columns (1) and (2) of Table A6 we show that the effect of DSL access remains mostly unchanged (see column (3) of Table 3) when we estimate equation (1) excluding from the sample individuals who changed their county of residence (column (1)) or residential address (column (2)) during the sample period. Results are similar if we exclude from the sample individuals who changed their postcode during the sample period.

As a placebo test, in column (3) we demonstrate that there is no significant correlation between lowspeed (dial-up) Internet and fertility using our IV approach for the period 2000-04, when there was practically no access to broadband in Germany (see also Bauernschuster et al. 2014). This placebo test supports a causal interpretation of our main findings. We also find no significant correlation between our instrumental variables and an index of fertility predictors built estimating the fitted values of a regression of fertility on the observable covariates (results available on request).

As displayed in column (4), our main result is robust to the exclusion of marital status from the set of controls. As shown in Tables A7 and A8, the exclusion of marital status leaves the results mostly unchanged relative to the benchmark specifications for fertility (in Tables 2 and 3). Furthermore, we show in Table A6 that the main result still holds when we control for previous number of children, which is a potentially endogenous variable, but clearly related to subsequent fertility (column (5)).

As reported in column (6) (Table A6), our key finding is robust to the inclusion of county-level contextual variables, such as the unemployment rate, population density, education (proportion of individuals with a university degree), and age structure (proportion of individuals of working age). In Tables A9 and A10 we present the full set of results to compare with the benchmark fertility specifications. We also show that our main results are mostly robust to excluding linear state-specific time trends (column (7)). The corresponding full set of results can be found in Tables A11 and A12.

Moreover, we show that our main results are not affected by the inclusion of local area fixed effects at a finer geographical level than the federal state, such as regional policy regions (Raumordungsregionen, ROR; Tables A13 and A14) or counties (Kreise and kreisfreie Städte; Table A15).

Since it is possible that individuals may need additional time to adjust their fertility plans in response to broadband access, as a further robustness check we re-estimate our baseline specification using one-year lagged DSL access as the main explanatory variable (column (8) of Table A6). For completeness, in Tables A16 and A17 we also report the full set of results to compare with the benchmark fertility specifications. Reassuringly, even when using lagged DSL access as our main explanatory variable, the results remain qualitatively and quantitatively very similar to the main analysis (in Tables 2 and 3).

While throughout the analysis we cluster standard errors by household, we could argue that the right level of clustering is not clear-cut, and that there may be ample room to overinterpret the degree of significance. To address this concern, we re-estimate the baseline specification, clustering the standard 
errors at the municipality or county level (columns (9) and (10), respectively). For completeness, we also present the full set of results to compare with the benchmark fertility specifications: in Tables A18 and A19 clustering at the municipality level, and in Tables A20 and A21 clustering at the county level. Importantly, we find that all the results are robust to this change.

We also re-estimate the entire analysis for fertility using only one instrument, that is, the dummy equal to ' 1 ' for households with distances to their MDF above the threshold of $4.2 \mathrm{~km}$, or ' 0 ' otherwise. The 2SLS estimates show that the effects of DSL connection are not sensitive to this modification (Tables A22 and A23). Finally, using the distance from the MDF as an alternative sole instrument yields similar results (Tables A24 and A25).

\section{Potential mechanisms}

What could be the mechanism underlying the relationship between broadband use and fertility? As discussed in the second section, the Internet may affect fertility through three main mechanisms: information, marriage, and work-family balance.

To test for the relative role of information, we analyse the OLS relationship between low-speed Internet and fertility. As shown in the previous section, our instruments are not correlated with access to low-speed Internet since they themselves affected the costs of switching to DSL technology. Thus, we cannot rely on the same IV approach to analyse the impacts of low-speed Internet on fertility. In fact, while working from home may require highspeed Internet, people could still obtain information with access only to a low-speed Internet connection. The OLS estimates displayed in Table A26 suggest that information plays a limited role in explaining the positive effects of broadband on fertility. There is no significant relationship between access to lowspeed Internet and fertility and, if anything, the coefficient for highly educated women aged $25-45$ is negative (coefficient -0.003 ; standard error 0.006).

Broadband access may also affect fertility through its potential effects on marriage (Bellou 2015). To construct our dependent variable, we exploit information on the year of marriage obtained from the marital histories, and build a dummy taking value ' 1 ' (or ' 0 ' otherwise) if the individual got married in a given year. We find a positive but non-significant relationship between access to high-speed Internet and the likelihood of getting married for highly educated women aged 25-45 (see column (1) of Table 5). We also test the marriage channel using an alternative definition of the dependent variable, that is, an indicator taking value ' 1 ' if the individual got married for the first time in a given year (or ' 0 ' otherwise). Irrespective of the chosen outcome, the results remain mostly unchanged. As previously noted, we present the entire set of results for fertility specifications without controls for marital status in Tables A7 and A8. Reassuringly, the 2SLS estimates show that the effects of DSL connection are not sensitive to the exclusion of marital status from the set of controls.

Furthermore, the fact that the results on fertility are driven by the decision to have a second or higher-order child rather than a first (as shown in Table A5), suggests that, while broadband may have an impact on marriage, this effect does not fully account for our main results on fertility.

With regard to the third mechanism, DSL technology provides individuals with more opportunities to carry out at least part of their work from home, thereby relaxing time constraints, especially among more educated women, and favouring the workfamily balance. Work flexibility and the possibility of reducing the costs of commuting may enable women, and in particular highly educated women, to reconcile motherhood and labour force participation (Dettling 2017).

To test this hypothesis, we first analyse the effects of DSL access on the likelihood of reporting any work from home, the likelihood of part-time vs. full-time work, working hours, and employment status, among highly educated women aged 25-45. We report the results of this analysis in columns (2)-(6) of Table 5. In our sample period, information on working from home is available only for 2009 . To minimize measurement error in teleworking, we add information from the associated study 'Families in Germany' (FiD) for 2010 and 2012, instead of just relying on the 2009 survey answers. The FiD panel survey is an extension of the SOEP, focusing on low-income families, single parents, and large families; for further information, see Schröder et al. (2013). Note that the point estimate is practically unchanged if we do not include individuals in the FiD sample but, given that in our sample period information on teleworking is available only in one wave, our identification power is substantially reduced when using only the regular SOEP database. It is also worth noting that all the results for fertility and its mechanisms are insensitive to the inclusion of the FiD sample in our analysis.

While sizable standard errors warrant caution in interpreting the results, in column (2) (Table 5) we find evidence that high-speed Internet increases the 
Table 5 Potential mechanisms for effect of broadband on fertility: highly educated women aged 25-45, Germany 2008-12

\begin{tabular}{|c|c|c|c|c|c|c|c|c|}
\hline $\begin{array}{l}\text { Dependent } \\
\text { variable: }\end{array}$ & $\begin{array}{c}(1) \\
\text { Got } \\
\text { married }\end{array}$ & $\begin{array}{l}(2) \\
\text { Work from } \\
\text { home }\end{array}$ & $\begin{array}{c}(3) \\
\text { Part-time } \\
\text { work }\end{array}$ & $\begin{array}{l}(4) \\
\text { Full-time } \\
\text { work }\end{array}$ & $\begin{array}{l}(5) \\
\text { Working } \\
\text { hours }\end{array}$ & $\begin{array}{c}(6) \\
\text { Not } \\
\text { working }\end{array}$ & $\begin{array}{c}(7) \\
\text { Childcare } \\
\text { (weekday) }\end{array}$ & $\begin{array}{c}(8) \\
\text { High life } \\
\text { satisfaction }\end{array}$ \\
\hline DSL subscription & $\begin{array}{c}0.052 \\
(0.041)\end{array}$ & $\begin{array}{r}0.294 * \\
(0.178)\end{array}$ & $\begin{array}{l}0.350 * * \\
(0.174)\end{array}$ & $\begin{array}{c}-0.240 \\
(0.167)\end{array}$ & $\begin{array}{c}-13.377 * * \\
(5.836)\end{array}$ & $\begin{array}{c}-0.110 \\
(0.142)\end{array}$ & $\begin{array}{r}3.693^{*} \\
(1.928)\end{array}$ & $\begin{array}{l}0.270 * * \\
(0.133)\end{array}$ \\
\hline $\begin{array}{l}\text { Mean of } \\
\text { dependent } \\
\text { variable }\end{array}$ & 0.026 & 0.243 & 0.474 & 0.320 & 28.21 & 0.207 & 5.353 & 0.219 \\
\hline $\begin{array}{l}\text { Standard deviation } \\
\text { of dependent } \\
\text { variable }\end{array}$ & 0.160 & 0.429 & 0.499 & 0.466 & 14.10 & 0.405 & 5.982 & 0.414 \\
\hline \multicolumn{9}{|l|}{ First stage ${ }^{1}$} \\
\hline Threshold & $\begin{array}{l}-0.121 * * * \\
(0.022)\end{array}$ & $\begin{array}{l}-0.127 * * * \\
(0.029)\end{array}$ & $\begin{array}{l}-0.124 * * * \\
(0.022)\end{array}$ & $\begin{array}{l}-0.124 * * * \\
(0.022)\end{array}$ & $\begin{array}{l}-0.114 * * * \\
(0.024)\end{array}$ & $\begin{array}{l}-0.124 * * * \\
(0.022)\end{array}$ & $\begin{array}{l}-0.124 * * * \\
(0.022)\end{array}$ & $\begin{array}{l}-0.126 * * * \\
(0.022)\end{array}$ \\
\hline 'No closer MDF' & $\begin{array}{c}-0.044 \\
(0.030)\end{array}$ & $\begin{array}{c}-0.024 \\
(0.040)\end{array}$ & $\begin{array}{c}-0.044 \\
(0.030)\end{array}$ & $\begin{array}{c}-0.044 \\
(0.030)\end{array}$ & $\begin{array}{l}-0.025 \\
(0.033)\end{array}$ & $\begin{array}{c}-0.044 \\
(0.030)\end{array}$ & $\begin{array}{l}-0.047 \\
(0.029)\end{array}$ & $\begin{array}{c}-0.045 \\
(0.030)\end{array}$ \\
\hline OPAL & $\begin{array}{c}-0.037 \\
(0.051)\end{array}$ & $\begin{array}{c}0.010 \\
(0.064)\end{array}$ & $\begin{array}{l}-0.034 \\
(0.051)\end{array}$ & $\begin{array}{l}-0.034 \\
(0.051)\end{array}$ & $\begin{array}{c}-0.009 \\
(0.051)\end{array}$ & $\begin{array}{c}-0.034 \\
(0.051)\end{array}$ & $\begin{array}{l}-0.035 \\
(0.051)\end{array}$ & $\begin{array}{l}-0.026 \\
(0.051)\end{array}$ \\
\hline $\begin{array}{l}F \text {-test of excluded } \\
\text { instruments }\end{array}$ & 14.33 & 9.849 & 15.13 & 15.13 & 11.62 & 15.13 & 15.35 & 15.74 \\
\hline Observations & 11,710 & 4,067 & 11,710 & 11,710 & 9,164 & 11,710 & 11,393 & 11,615 \\
\hline
\end{tabular}

${ }^{1}$ See 'Empirical method' section for details of broadband variables.

Notes: Standard errors are reported in parentheses and are clustered at the household level. All models include controls for education, age and its quadratic term, sex, an indicator for rural area, marital status, occupational status, migration background, and log of net household income. All regressions further include state and survey year fixed effects, as well as state-specific time trends. The $F$-test for excluded instruments refers to the Kleibergen-Paap $F$-statistic.

*Significant at 10 per cent; **significant at 5 per cent; ***significant at 1 per cent.

Source: As for Table 1.

likelihood of working from home by 29.4 percentage points. Columns (3) and (4) suggest that access to DSL encourages part-time vs. full-time work. Consistent with this, in column (5) we find that the overall number of hours worked diminishes with broadband access (by approximately 13 hours per week, reflecting the observed shift towards parttime work). While the point estimate in column (6) suggests a positive effect of broadband on the level of women's employment (extensive margin), there is no evidence of a significant effect. This result is in line with previous literature suggesting limited evidence of causal effects of high-speed Internet on employment (see Falck 2017 for a comprehensive review). Thus, taken together, our evidence suggests that broadband facilitates part-time vs. full-time work, with little effect on women's overall labour force participation.

We also investigate the effects of DSL access on time spent on childcare activities per weekday and life satisfaction (columns (7) and (8)). We choose to focus on hours spent on childcare on a typical weekday, given the potential conflict between working time and family time. Access to DSL significantly increases time spent on childcare, by approximately 3.7 hours on an average weekday. Consistent with the reasoning that the Internet may enable highly educated women to be more flexible and better organized with their use of time, we find evidence of a significant effect of DSL on the likelihood of reporting high life satisfaction. Among less-educated women, however, we find no evidence of significant effects on teleworking, labour market outcomes, childcare, or life satisfaction (Table A27).

\section{Conclusion}

In the analysis reported in this paper, we studied the effects of access to broadband on fertility in a low-fertility, high-income context: Germany. Using individual-level data, we found a robust and positive, albeit imprecise, impact of broadband on the fertility of highly educated women aged 25-45. In particular, broadband significantly increased the likelihood of progressing to a second or higher-order child. On the contrary, we found no evidence of effects on individuals under the age of 25 . We showed that broadband access significantly increased the share of women reporting working from home and working part-time. It is worth noting that we estimated LATEs, and that the results are mainly 
heterogeneous across groups, with the largest impacts among highly educated women over 30 . Furthermore, we confirmed the positive effects of broadband on fertility when using county-level data on total fertility.

Building on the existing literature, we cast three main mechanisms through which the Internet may affect fertility: information, marriage, and workfamily balance. The findings of our analyses are consistent with the third hypothesis: that broadband access allows highly educated women to reconcile work and motherhood more easily, which in turn may promote fertility.

The lack of annual information on teleworking limited our ability to fully disentangle the mechanisms at play, and in particular to document how access to broadband might have changed the daily life of individuals of working and reproductive age. This is an important limitation of our study. Given the increasing number of firms that adopt smart working policies, flexible hours, and telecommuting programmes, exploring the effects of these work practices on fertility and other life course choices is a promising and important avenue of research. Moreover, access to better data on working conditions and schedules would allow researchers to explore the potential mechanisms further, by detecting and assessing the controlled direct effect of a treatment or using front-door difference-indifferences estimators (Acharya et al. 2016; Glynn and Kashin 2017, 2018; Pearl and Mackenzie 2018).

Overall, our findings suggest that increasing access to high-speed Internet may promote fertility among highly educated women by easing the burden of balancing work and family duties. This may be particularly important in countries such as Germany, which have been lagging behind in terms of the share of telecommuters compared with other advanced economies (Brenke 2016). Access to high-speed Internet has reduced the working hours of highly educated women, thereby increasing the share of part-time workers. However, it should be noted that these are short-term effects and, overall, the roll-out of broadband has been shown to have small but positive effects on the level of employment (Falck 2017). Furthermore, more generous childcare policies can mitigate these negative effects on working hours. Indeed, the recent reforms to childcare policy promoted by the German government have been shown to have significant and positive effects on fertility by reducing the opportunity costs of childbearing (Bauernschuster et al. 2016; Raute 2017; Riphahn and Wiynck 2017; Cornelissen et al. 2018).

The downside of our findings is that broadband might introduce a 'digital divide' in fertility, allowing highly educated individuals to realize their fertility goals, while not improving those chances for lesseducated individuals, who tend to be employed in less flexible occupations. Further research is also needed on this avenue.

\section{Notes}

1 Francesco C. Billari is based in the Department of Social and Political Sciences and the Carlo F. Dondena Centre for Research on Social Dynamics and Public Policy, Bocconi University. Osea Giuntella is based at the University of Pittsburgh and is affiliated with IZA. Luca Stella is based at the Carlo F. Dondena Centre for Research on Social Dynamics and Public Policy, Bocconi University and is affiliated with IZA. Please direct all correspondence to Luca Stella at Via Guglielmo Röntgen, 1, 20136 Milano, Italy; or by Email: luca.stella@unibocconi.it

2 This project has received funding from the European Research Council (ERC) under the European Union's Horizon 2020 research and innovation programme (grant agreement no. 694262), project DisCont-Discontinuities in Household and Family Formation. We thank the Editor and three anonymous referees whose careful review led to many improvements. We are grateful to Nicoletta Balbo, Camilla Billari, Alessandro Di Nallo, Jan Goebel, Melanie Guldi, Marco Le Moglie, Jan Marcus, Luca Pesando, and Valentina Rotondi; seminar attendants at the IAB in Nuremberg, the University of Sheffield, the IZA Workshop 'Labour Productivity and the Digital Economy' at the OECD, and the DIW in Berlin; and participants at the 2018 Population Association of America conference in Denver and the 2017 European Society of Population Economics conference in Glasgow for insightful comments and suggestions. We further thank the DIW for access to the SOEP data and, in particular, Jan Goebel for his permanent support.

\section{References}

Acharya, A., M. Blackwell, and M. Sen. 2016. Explaining causal findings without bias: Detecting and assessing direct effects, American Political Science Review 110 (3): 512-529.

Albanesi, S. and C. Olivetti. 2016. Gender roles and medical progress, Journal of Political Economy 124(3): 650-695.

Balbo, N., and N. Barban. 2014. Does fertility behavior spread among friends?, American Sociological Review 79(3): 412-431. 
Balbo, N., F. C. Billari, and M. Mills. 2013. Fertility in advanced societies: A review of research, European Journal of Population/Revue Européenne de Démographie 29(1): 1-38.

Bauernschuster, S., O. Falck, and L. Woessmann. 2014. Surfing alone? The Internet and social capital: Evidence from an unforeseeable technological mistake, Journal of Public Economics 117: 73-89.

Bauernschuster, S., T. Hener, and H. Rainer. 2016. Children of a (policy) revolution: The introduction of universal child care and its effect on fertility, Journal of the European Economic Association 14(4): 975-1005.

Bellou, A. 2015. The impact of Internet diffusion on marriage rates: Evidence from the broadband market, Journal of Population Economics 28(2): 265-297.

Bernardi, L., S. Keim, and H. Von Der Lippe. 2007. Social influences on fertility: A comparative mixed methods study in Eastern and Western Germany, Journal of Mixed Methods Research 1(1): 23-47.

Billari, F. C. and H.-P. Kohler. 2004. Patterns of low and lowest-low fertility in Europe, Population Studies 58 (2): 161-176.

Bittman, M. and J. Wajcman. 2000. The rush hour: The character of leisure time and gender equity, Social Forces 79(1): 165-189.

Bongaarts, J., and S. C. Watkins. 1996. Social interactions and contemporary fertility transitions, Population and Development Review 22: 639-682.

Boserup, E.1976. Environment, population, and technology in primitive societies, Population and Development Review 2: 21-36.

Bremhorst, V., M. Kreyenfeld, and P. Lambert. 2016. Fertility progression in Germany: An analysis using flexible nonparametric cure survival models, Demographic Research 35: 505-534.

Brenke, K. 2016. Home offices: Plenty of untapped potential, DIW Economic Bulletin 6(8): 95-104.

Buber-Ennser, I., R. Panova, and J. Dorbritz. 2013. Fertility intentions of university graduates, Demográfia English Edition 56(5): 5-34.

Bundesministerium für Wirtschaft und Technologie. 2010. Bericht zum Breitbandatlas 2010 des Bundesministeriums für Wirtschaft und Technologie, Available from: https:// www.bmvi.de/SharedDocs/DE/Anlage/Digitales/berichtzum-breitbandatlas-ende-2010-ergebnisse.pdf?_blob= publicationFile (accessed: 5 December 2018).

Castells, M. 2002. The Internet Galaxy: Reflections on the Internet, Business, and Society. New York: Oxford University Press on Demand.

Conley, D. 2009. Elsewhere, USA: How we got from the Company man, Family Dinners, and the Affluent Society to the Home Office, BlackBerry Moms, and Economic Anxiety. New York, NY: Pantheon Books.
Cornelissen, T., C. Dustmann, A. Raute, and U. Schö nberg. 2018. Who benefits from universal child care? estimating marginal returns to early child care attendance, Journal of Political Economy forthcoming.

de V. Cavalcanti, T. V. and J. Tavares. 2008. Assessing the 'engines of liberation': home appliances and female labor force participation, The Review of Economics and Statistics 90(1): 81-88.

Dettling, L. J. 2017. Broadband in the labor market: the impact of residential high-speed internet on married women's labor force participation, Industrial and Labor Relations Review 70(2): 451-482.

Di Maggio, P., E. Hargittai, W. R. Neuman, and J. P. Robinson. 2001. Social implications of the Internet, Annual Review of Sociology 27(1): 307-336.

Falck, O. 2017. Does broadband infrastructure boost employment?, IZA World of Labor. Available from: https://wol.iza.org/articles/does-broadband-infrastructureboost-employment/long (accessed: 5 December 2018).

Falck, O., R. Gold, and S. Heblich. 2014. E-lections: Voting Behavior and the Internet, The American Economic Review 104(7): 2238-2265.

Glynn, A. N. and K. Kashin. 2017. Front-door differencein-differences estimators, American Journal of Political Science 61(4): 989-1002.

Glynn, A. N. and K. Kashin. 2018. Front-door versus backdoor adjustment with unmeasured confounding: Bias Formulas for front-door and hybrid adjustments with application to a job training program, Journal of the American Statistical Association. Forthcoming.

Goldin, C. and L. F. Katz. 2002. The power of the pill: Oral contraceptives and women's career and marriage decisions, Journal of Political Economy 110(4): 730-770.

Goldscheider, F., E. Bernhardt and T. Lappegård. 2015. The gender revolution: A framework for understanding changing family and demographic behavior, Population and Development Review 41(2): 207-239.

Goldstein, J., W. Lutz, and M. R. Testa. 2003. The emergence of sub-replacement family size ideals in Europe, Population Research and Policy Review 22(5): 479-496.

Greenwood, J., A. Seshadri, and M. Yorukoglu. 2005. Engines of liberation, Review of Economic Studies 72 (1): 109-133.

Guldi, M. and C. M. Herbst. 2017. Offline effects of online connecting: the impact of broadband diffusion on teen fertility decisions, Journal of Population Economics 30 (1): 69-91.

Hank, K. 2002. Regional social contexts and individual fertility decisions: A multilevel analysis of first and second births in Western Germany, European Journal of Population/Revue Européenne de Démographie 18(3): 281-299.

Hank, K. and M. Kreyenfeld. 2003. A multilevel analysis of child care and women's fertility decisions in Western Germany, Journal of Marriage and Family 65(3): 584-596. 
Hargittai, E. 2010. Digital na(t)ives? Variation in internet skills and uses among members of the 'net generation', Sociological Inquiry 80(1): 92-113.

Haub, C. 2012. Fertility rates in low birth-rate countries, 1996-2011, Population Reference Bureau. Available from: https://www.prb.org/low-fertility-countries-tfr-2/

Hofmann, B. and K. Hohmeyer. 2013. Perceived economic uncertainty and fertility: evidence from a labor market reform, Journal of Marriage and Family 75(2): 503-521.

Jaeger, D., T. Joyce, and R. Kaestner. 2016. Does Reality TV Induce Real Effects? On the Questionable Association Between 16 and Pregnant and Teenage Childbearing, IZA Discussion Papers 10317, Institute for the Study of Labor (IZA).

Jonen, G. and T. Eckardt. 2006. The education system in the Federal Republic of Germany 2004. Secretariat of the Standing Conference of the Ministers of Education (KMK).

Kearney, M. S. and P. B. Levine. 2015. Media influences on social outcomes: The impact of MTV's 16 and pregnant on teen childbearing, The American Economic Review 105(12): 3597-3632.

Kohler, H.-P. 2001. Fertility and Social Interaction: An Economic Perspective. Oxford: Oxford University Press.

Kohler, H.-P., J. R. Behrman, and S. C. Watkins. 2001. The density of social networks and fertility decisions: evidence from South Nyanza District, Kenya, Demography 38(1): 43-58.

Kohler, H.-P., F. C. Billari, and J. A. Ortega. 2002. The emergence of lowest-low fertility in Europe during the 1990s, Population and Development Review 28(4): 641-680.

La Ferrara, E., A. Chong, and S. Duryea. 2012. Soap operas and fertility: evidence from Brazil, American Economic Journal: Applied Economics 4(4): 1-31.

Lesthaeghe, R. 2010. The unfolding story of the second demographic transition, Population and Development Review 36(2): 211-251.

McDonald, P. 2000. Gender equity in theories of fertility transition, Population and Development Review 26(3): 427-439.
Morgan, S. P. and M. G. Taylor. 2006. Low fertility at the turn of the twenty-first century, Annual Review of Sociology 32: 375-399.

Pearl, J. and D. Mackenzie. 2018. The Book of Why: The New Science of Cause and Effect. Grand Haven, MI: Basic Books.

Philipov, D. 2009. Fertility intentions and outcomes: the role of policies to close the gap, European Journal of Population/Revue Européenne de Démographie 25(4): 355-361.

Raute, A. 2017. Can financial incentives reduce the baby gap? Evidence from a reform in maternity leave benefits, Journal of Public Economics forthcoming.

Riphahn, R. T. and F. Wiynck. 2017. Fertility effects of child benefits, Journal of Population Economics 30(4): 11351184.

Rosenfeld, M. J. and R. J. Thomas. 2012. Searching for a mate: The rise of the Internet as a social intermediary, American Sociological Review 77(4): 523-547.

Schröder, M., R. Siegers, and C. K. Spiess. 2013. Familien in Deutschland-FiD, Schmollers Jahrbuch 133(4):595-606.

Sedgh, G., L. B. Finer, A. Bankole, M. A. Eilers, and S. Singh. 2015. Adolescent pregnancy, birth, and abortion rates across countries: levels and recent trends, Journal of Adolescent Health 56(2): 223-230.

Stock, J. H. and M. Yogo. 2002. Testing for weak instruments in linear IV regression, NBER Technical Working Papers.

Trudeau, J. 2016. The role of new media on teen sexual behaviors and fertility outcomes - the case of 16 and pregnant, Southern Economic Journal 82(3): 975-1003.

Wagner, G., J. Frick, and J. Schupp. 2007. The German Socio-Economic Panel study (SOEP) - scope, evolution, and enhancements, Schmollers Jahrbuch 127: 139-169.

Wajcman, J. 2015. Pressed for Time: The Acceleration of Life in Digital Capitalism. Chicago: University of Chicago Press.

Ziefle, A. and M. Gangl. 2014. Do women respond to changes in family policy? A quasi-experimental study of the duration of mothers' employment interruptions in Germany, European Sociological Review 30(5): 562-581. 